\title{
Study of the Physiological Dynamics of Cadmium Accumulation in Two Varieties of Rice with Different Cadmium-Accumulating Properties
}

\author{
Shangdu Zhang $\mathbb{D}^{1,2}$ Xiang Wu, ${ }^{2}$ Ju Peng, ${ }^{2}$ Xiufei Meng, ${ }^{2}$ Bangzhi Shi, ${ }^{2}$ Leliang Zhou, ${ }^{2}$ \\ and Lianyang Bai $\mathbb{D}^{1,3}$ \\ ${ }^{1}$ Long Ping Branch of Graduate School, Central South University, Changsha, Hunan 410125, China \\ ${ }^{2}$ Guizhou Rice Research Institute, Guizhou Academy of Agricultural Sciences, Guiyang, Guizhou 550006, China \\ ${ }^{3}$ Hunan Agricultural Biotechnology Research Institute, Hunan Academy of Agricultural Sciences, Changsha, \\ Hunan 410125, China
}

Correspondence should be addressed to Lianyang Bai; lybai@hunaas.cn

Received 8 November 2021; Accepted 28 November 2021; Published 10 December 2021

Academic Editor: Wenneng Wu

Copyright (c) 2021 Shangdu Zhang et al. This is an open access article distributed under the Creative Commons Attribution License, which permits unrestricted use, distribution, and reproduction in any medium, provided the original work is properly cited.

\begin{abstract}
This study focused on cadmium (Cd) uptake by two rice varieties, Yuzhenxiang (YZX) and Xiangwanxian 12 (XWX), which differ in their capacity to accumulate Cd, i.e., XWX > YZX. Treatments with three different gradients of soil Cd concentrations showed that with the increase in soil Cd concentration gradient, the Cd content in each rice plant organ also increased, i.e., Cd-3 $>\mathrm{Cd}$ $2>\mathrm{Cd}-1$. The trend in the $\mathrm{Cd}$ content of each organ was such that the farther the organ from the root, the lower its Cd content, i.e., root $>$ stem and sheath > leaf > grain. We observed that for all four growth stages, the booting stage is the key stage in terms of Cd absorption, where the highest levels of accumulation are observed, that is, booting stage $>$ full heading stage $>$ tillering stage$>$ maturity stage. Of the two cultivars, XWX had higher SOD, POD, and CAT activities but lower MDA content. In contaminated soils, SOD, POD, and CAT activities increased gradually with the increase in Cd concentration, while MDA content decreased, which indicated that the low Cd variety XWX had an advantage over the high Cd variety YZX. Through the comparative analysis of photosynthetic physiology, it was found that the low-Cd-accumulating rice variety XWX appeared more tolerant to Cd, while the high-Cd-accumulating rice YZX was more sensitive. Therefore, the low Cd rice variety XWX was more suitable for planting safe rice in Cd-polluted paddy fields.
\end{abstract}

\section{Introduction}

Rice (Oryza sativa L.) is the main food crop in China, with more than half of the population consuming rice as their staple food. The rapid development following industrialization in China has not only provided huge economic benefits but also caused a large amount of environmental pollution, including numerous types of heavy metals that have entered into the agricultural soil. Heavy metal pollution in agricultural soil mainly includes cadmium (Cd), chromium $(\mathrm{Cr})$, mercury $(\mathrm{Hg})$, lead $(\mathrm{Pb})$, and nickel $(\mathrm{Ni})$ [1]. According to the National Soil Pollution Investigation Bulletin jointly published by the Ministry of Environmental
Protection and the Ministry of Land and Resources in 2014 [2], the above-standard rate of heavy metal pollution in China's cultivated soil reached $19.4 \%$. Cd is the number one contaminant in heavy metal pollution, and the threshold rate beyond which the standard is exceeded is $7.0 \%$. Cd is a toxic heavy metal element with strong biological activity and is a nonessential element for plants, whose growth and development are hindered by excessive accumulation [3]. Cd can be transferred from rice to the human body through the food chain, thus causing harm to human health [4].

Following the occurrence of $\mathrm{Cd}$ stress, plants will activate evolved self-protection defense mechanisms, such as increasing the activity of superoxide dismutase (SOD), 
peroxidase (POD), catalase (CAT), and other antioxidant enzymes and reducing the accumulation of membrane lipid malondialdehyde (MDA). These mechanisms can effectively reduce the damage to plants caused by Cd stress [5-7].

Cd stress will inhibit plant photosynthesis, and the degree of inhibition is related to plant species, growth period, environmental conditions, $\mathrm{Cd}$ stress concentration, time, and many other factors. The inhibition of plant photosynthesis by heavy metals is due to their effects on electron transport in the process of photosynthesis and in destroying chloroplast integrity [8]. Cd stress damages plant photosynthesis mainly through disruption of physiological processes such as photosynthesis rate (Photo, Pn), stomatal conductance $(\mathrm{Gs})$, intercellular $\mathrm{CO}_{2}$ concentration $(\mathrm{Ci})$, and transpiration rate (Trmmol, Tr) [9].

A low concentration of $\mathrm{Cd}$ in soil generally has no effect on rice yield, given that rice has a high capacity for $\mathrm{Cd}$ adsorption; when the soil Cd content is higher, however, $\mathrm{Cd}$ stresses affect rice plant physiological and biochemical metabolism, causing a series of changes in these characteristics, which induces disorders in cell metabolism and ultimately inhibits rice growth and development. In studies of medium and high concentrations of Cd pollution stress, there are currently few reports describing the characterization of Cd content, antioxidant enzyme activity, and photosynthesis parameters in various organs of rice. In order to provide a theoretical basis for the breeding of new $\mathrm{Cd}$ tolerant rice varieties, this study took Yuzhenxiang (YZX) and Xiangwanxian 12 (XWX) as the research objects, based on their different patterns of $\mathrm{Cd}$ accumulation, and analyzed their physiological and biochemical characteristics under treatment with different concentrations of soil $\mathrm{Cd}$, so as to provide a theoretical basis for the breeding of new Cdtolerant rice varieties.

\section{Materials and Methods}

\subsection{Materials}

2.1.1. Experimental Material. The experimental materials were the high-Cd-accumulating variety YZX and the lowCd-accumulating variety XWX, which are the result of selection by predecessors over many years and many points of pot cultivation and field verification [10]. The two rice varieties were bred and provided by Hunan Rice Research Institute and were suitable for the double cropping of late rice in the rice growing area of Hunan Province, with a growth period of $115 \pm 2 \mathrm{~d}$.

2.1.2. Summary of the Test Site. The experiment was conducted in the Spring Science Research Base of the Hunan Academy of Agricultural Sciences-the breeding and identification base of rice varieties with low Cd accumulation $\left(113^{\circ} 26^{\prime} 57^{\prime \prime} \mathrm{E}, 28^{\circ} 29^{\prime} 36^{\prime \prime} \mathrm{N}\right)$ in Chunhua Town, Changsha County, Changsha City. The experimental site is located in a typical section of the middle subtropical region, with an average annual temperature of $17.2^{\circ} \mathrm{C}$ and an average annual rainfall of $1361 \mathrm{~mm}$, belonging to the double-cropping rice production area.
In this experiment, the pool planting identification area of the breeding and identification base of rice varieties with low $\mathrm{Cd}$ accumulation was selected, and the irrigation and drainage design was adopted to control the uniformity of factors such as soil Cd content, $\mathrm{pH}$, and water content in the tank, and the high-precision soil moisture, $\mathrm{pH}$, and temperature monitoring system and remote control system were matched.

2.1.3. Test Treatment and Method. The two tested rice varieties were sown on June 13,2018, and two grain seedlings were transplanted on July 1,2018. Six rows were planted in each plot, with 14 stumps for each row. The spacing between plants and rows was $17 \times 20 \mathrm{~cm}$, with a protection row set between. Samples were taken at the tillering (August 4, 2018), booting (August 16, 2018), full heading (September 14, 2018), and maturity stages (September 20, 2018) of rice. The pool identification area contains natural $\mathrm{Cd}$ concentration-treated soil, and according to the $\mathrm{Cd}$ concentration, the soil was divided into Cd-1, Cd-2, and Cd-3 gradients. Fertilizer management: no basal fertilizer, urea $(60 \mathrm{~kg} / \mathrm{ha})$, and potassium chloride $(30 \mathrm{~kg} / \mathrm{ha})$ were applied for tillering. Water management: flooding in the early stage, moist irrigation after heading, dry soil naturally in the week before harvest, and other management aspects are the same as in the field. In the above four growth stages of rice, the $\mathrm{Cd}$ content in roots, stem sheath, leaves, and grains was measured. The photosynthetic parameters, $\mathrm{Pn}, \mathrm{Gs}, \mathrm{Ci}$, and $\mathrm{Tr}$, of the top leaves were measured. The activity of the antioxidant enzymes SOD, POD, and CAT and the content of MDA were measured in the top leaves.

\subsection{Determination Items and Methods}

2.2.1. Soil Physical and Chemical Properties Detection. The soil of $0-20 \mathrm{~cm}$ in the tillage layer of the paddy field was taken before rice transplantation, and the physical and chemical indexes were detected. The soil was air-dried to remove rock and animal and plant residues, then crushed through a 100-target sieve, and sealed for use. The method was repeated three times for each sample. Soil physical and chemical indexes and determination methods are as follows: Soil total Cd (ST-Cd) was determined by atomic spectrophotometry [11], and soil effective Cd (SE-Cd) was determined by atomic absorption spectrometry [12]. Total nitrogen (TN) was determined using the Kjeldahl method [13], available nitrogen (AN) was determined by the alkali-hydrolytic diffusion method [14], and total phosphorus (TP) was determined by the perchloric acid-sulfuric acid method [15]. Available phosphorus (AP) was determined by spectrophotometry [16], and total potassium (TK) was determined by sodium hydroxide melting [17]. Available potassium (AK) was determined by flame spectrophotometry [18], and $\mathrm{pH}$ was determined using the potentiometric method [19]. Soil organic matter (SOM) was determined by REDOX colorimetry [20].

Soil samples were taken from rice fields of Cd-1, Cd-2, and $\mathrm{Cd}-3$, each with different $\mathrm{Cd}$ concentrations, for the characterization of physical and chemical indicators. Samples were taken from each tested variety area of each treatment, for which there were three replicates. These results are shown in Table 1. 
TABLe 1: Physical and chemical properties of soil samples.

\begin{tabular}{lccc}
\hline Test item & \multicolumn{3}{c}{ Soil treatment } \\
& Cd-1 & Cd-2 & Cd-3 \\
\hline ST-Cd $(\mathrm{mg} / \mathrm{kg})$ & $0.16 \pm 0.00 \mathrm{c}$ & $0.56 \pm 0.00 \mathrm{~b}$ & $0.89 \pm 0.00 \mathrm{a}$ \\
SE-Cd $(\mathrm{mg} / \mathrm{kg})$ & $0.05 \pm 0.00 \mathrm{c}$ & $0.27 \pm 0.00 \mathrm{~b}$ & $0.53 \pm 0.00 \mathrm{a}$ \\
TN $(\mathrm{g} / \mathrm{kg})$ & $0.85 \pm 0.02 \mathrm{c}$ & $1.55 \pm 0.02 \mathrm{~b}$ & $1.69 \pm 0.01 \mathrm{a}$ \\
AN $(\mathrm{mg} / \mathrm{kg})$ & $71.33 \pm 0.88 \mathrm{~b}$ & $118.67 \pm 0.88 \mathrm{a}$ & $118.33 \pm 1.20 \mathrm{a}$ \\
TP $(\mathrm{g} / \mathrm{kg})$ & $0.35 \pm 0.01 \mathrm{c}$ & $0.45 \pm 0.01 \mathrm{~b}$ & $0.49 \pm 0.01 \mathrm{a}$ \\
AP $(\mathrm{mg} / \mathrm{kg})$ & $4.30 \pm 0.06 \mathrm{c}$ & $6.47 \pm 0.09 \mathrm{a}$ & $5.37 \pm 0.03 \mathrm{~b}$ \\
TK $(\mathrm{g} / \mathrm{kg})$ & $11.80 \pm 0.15 \mathrm{~b}$ & $11.87 \pm 0.09 \mathrm{~b}$ & $13.40 \pm 0.10 \mathrm{a}$ \\
AK $(\mathrm{mg} / \mathrm{kg})$ & $40.67 \pm 1.20 \mathrm{~b}$ & $33.67 \pm 1.20 \mathrm{c}$ & $51.33 \pm 0.88 \mathrm{a}$ \\
pH & $6.54 \pm 0.00 \mathrm{~b}$ & $7.03 \pm 0.01 \mathrm{a}$ & $6.09 \pm 0.01 \mathrm{c}$ \\
SOM $(\mathrm{g} / \mathrm{kg})$ & $11.17 \pm 0.03 \mathrm{c}$ & $27.17 \pm 0.09 \mathrm{a}$ & $25.80 \pm 0.12 \mathrm{~b}$ \\
\hline
\end{tabular}

Note. The data in the table are mean \pm standard error. ST-Cd, soil total Cd; SE-Cd, soil effective Cd; TN, total nitrogen; AN, available nitrogen; TP, total phosphorus; AP, available phosphorus; TK, total potassium; AK, available potassium; SOM, soil organic matter.

2.2.2. Determination of $\mathrm{Cd}$ Content in Rice. After the rice plants were cleaned, they were washed with deionized water, and the water on the surface was absorbed using absorbent paper. The roots, stems and sheathing, leaves, and rice were decomposed into paper bags and numbered, then placed into the oven at $110^{\circ} \mathrm{C}$ for 30 minutes, and dried at $80^{\circ} \mathrm{C}$ until the weight was constant. The root system, stem sheath, leaves, and husked rice (husked using a huller with a polyurethane roller to prevent metal contamination) were pulverized and screened over a 100-point sieve before being stored in a dryer. Cd content in the samples was determined by ICP-OES and repeated three times [21].

2.2.3. Antioxidant Enzyme Index Determination. At the tillering, booting, full heading, and maturity stages of rice, the upper leaves were taken in the field, wrapped with tin foil paper and numbered, and then placed in the liquid nitrogen tank for snap-freezing. After returning to the laboratory, liquid nitrogen was added for grinding, weighing (approximately $0.2 \mathrm{~g}$ per serving), and tube loading $(2 \mathrm{~mL}$ centrifuge tube); then, the samples were numbered and placed in the refrigerator at $-80^{\circ} \mathrm{C}$ for reserve.

The SOD, POD, and CAT activities and MDA content were measured using the corresponding kits (Nanjing Jiancheng Bioengineering Institute, Nanjing, China).

2.2.4. Determination of Photosynthetic Index. At the same time as the determination of antioxidant enzymes, the LI6400 portable photosynthetic system analyzer was used to determine the top leaves of rice in the four growth periods from 09:00 to 11:00 in the morning on sunny days. The determination of $\mathrm{Pn}, \mathrm{Gs}, \mathrm{Ci}$, and $\mathrm{Tr}$ was repeated three times, and the average value was taken. The light intensity was set to $1000 \mu \mathrm{mol} \cdot \mathrm{m}^{-2} \cdot \mathrm{s}^{-1}$, and the gas flow rate was $600 \mu \mathrm{mol} \cdot \mathrm{s}^{-1}$.

2.3. Data Processing. The data obtained were statistically analyzed using Microsoft Excel 2007 software, an OVA was analyzed using DPS software, and the significance test of mean was conducted using Duncan's new complex range method $(P<0.05)$. Origin 7.5 and Adobe Illustrator CS5 were used for illustrations.

\section{Results}

3.1. Effects of Cd Stress on Antioxidant Enzymes of Rice. Under different Cd concentrations, the activity of antioxidant enzymes (SOD, POD, and CAT) and MDA content in the leaves of the two tested rice varieties at different growth stages are shown in Table 2.

3.1.1. Comparison of Responses between Different Rice Varieties. The results show that the SOD activity of YZX was significantly lower than that of XWX, accounting for $66.7 \%$, and the difference was significant except in the full heading stage Cd-2 and mature stage Cd-3 (accounting for 16.7\%). There was no significant difference in POD activity between YZX and XWX at the booting, full heading, and maturity stages in Cd-1 treatment. However, the POD activity of YZX was significantly lower than that of XWX at the tillering stage. Under Cd-2 treatment, the POD activity of XWX was significantly higher than that of YZX at the tillering, full heading, and maturity stages, but there was no significant difference between the POD activity of XWX and YZX at the booting stage. In Cd-3 treatment, the POD activity of XWX was significantly higher than that of YZX in all four growth stages. The comparison of CAT activity showed the same, and the CAT activity in YZX was mostly significantly lower than that of XWX. The MDA content of YZX was significantly higher than that of XWX for most stages and treatments. There was no significant difference in MDA content between the full heading stage in Cd-1 treatment and maturity stage in Cd-2 and Cd-3 treatments.

3.1.2. Comparison of Responses to Different Concentrations of Cd Pollution in Soils. There were significant differences in $\mathrm{SOD}, \mathrm{POD}$, and CAT activities between the two rice varieties grown in soils with different $\mathrm{Cd}$ concentrations, which also showed similar trends of increasing with the increase in $\mathrm{Cd}$ concentration, that is, Cd-3 $>\mathrm{Cd}-2>\mathrm{Cd}-1$. The MDA content was significantly different, though it showed a similar but opposite trend of decreasing with the increase in $\mathrm{Cd}$ pollution concentration, that is, Cd- $1>\mathrm{Cd}-2>\mathrm{Cd}-3$.

\subsubsection{Comparison of Responses according to Different Growth} Stages. There was no significant difference in SOD activity between the two rice varieties at different growth stages, but the enzyme activity fluctuated significantly between different rice varieties under different soil $\mathrm{Cd}$ concentrations. The highest values of SOD activity for Cd-1 and Cd-2 were observed at the booting stage, and the highest values for Cd-3 were at the full heading stage. With prolongation of the growth period, the POD activity showed an obvious decreasing trend, that is, tillering stage $>$ booting stage $>$ full heading stage $>$ maturity stage, but the significance of the difference varied by rice variety and soil Cd concentration. There were significant differences in CAT activity, but the 


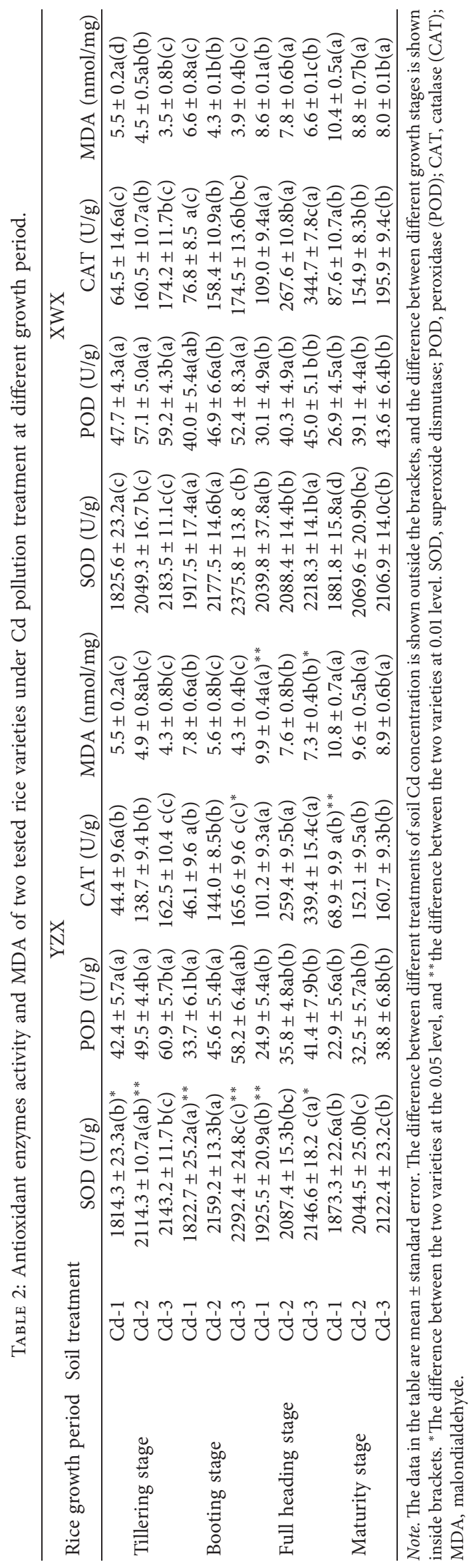


enzyme activity fluctuated significantly between different soil Cd treatments and varieties, and no obvious trend was found. The variation trend in CAT values for the two tested varieties was consistent in Cd-1 and Cd-2, with the value peaking at the full heading stage and then decreasing. CAT values in Cd-3 showed a gradual upward trend with the extension of the growth period, with the highest value at the maturity stage. The trend of MDA content was opposite to that of POD activity, both of which showed an obvious trend of increasing with the prolongation of growth period, that is, tillering stage $<$ booting stage $<$ full heading stage $<$ maturity stage.

\subsection{Changes of Photosynthetic Parameters in Cd Environment.} Through data processing, it was found that there were significant differences among the photosynthetic parameters $\mathrm{Pn}, \mathrm{Gs}, \mathrm{Ci}$, and $\mathrm{Tr}$ of leaves according to differing $\mathrm{Cd}$ concentration pollution treatments, rice variety, and growth and development stages (Table 3 ).

\subsubsection{Comparison of Photosynthetic Parameters at Different} Growth Stages. For Pn, there was a significant effect on Pn between the two varieties. For Gs, there were no obvious trends or significant differences observed. For Ci, after the tillering stage of growth, the effects of both varieties on $\mathrm{Ci}$ were consistent. For Tr, in the Cd-1 and Cd-3 treatments, there was a significant difference in the performance of the two varieties in terms of $\mathrm{Tr}$, while there was no significant difference in the Tr of the two varieties in the Cd-2 treatment (Table 3).

\subsubsection{Comparison of Photosynthetic Parameters for the} Treatment of Different Cd Soils. The Pn and Gs values of the two tested varieties were significantly affected by different Cd soil treatments, and there was an obvious trend in the change. The values for Cd-2 were the highest, while the values for Cd-1 and Cd-3 were lower. In other words, the Pn was higher in Cd-2 than in the other Cd soil treatments at different growth stages, and the Pn of Cd-1 and Cd-3 varied greatly with the change in growth stage. The $\mathrm{Ci}$ values differed significantly with different Cd treatments, but the trends were not consistent between YZX and XWX. In most growth periods, the effects of $\mathrm{Cd}$ soil treatment on $\mathrm{Tr}$ were consistent in both varieties. With the increase in the $\mathrm{Cd}$ concentration in soil, all $\mathrm{Tr}$ values were increased, i.e., Cd$3>$ Cd-2 $>$ Cd -1 .

3.2.3. Comparison among Four Growth Stages. Pn variation trend: No significant effect on Pn was found for the tillering stage of both cultivars, but a significant effect on Pn was observed at booting, full heading, and maturity stages. Hence, the Pn value was significantly affected by different growth stages, and there was an obvious trend in the change. Under Cd-1 and Cd-3 treatments, the two varieties showed a gradual decrease in $\mathrm{Pn}$ with the extension of the growth period. However, the lowest Pn value was observed for Cd-2 at the booting stage, which then gradually increased, and in each case, the Pn value was higher under Cd-2 than the corresponding Cd-1 and Cd-3 for each growth stage. The variation trend in Gs was as follows: The Gs value gradually decreased with the extension of the growth stage, that is, tillering stage $>$ booting stage $>$ full heading stage $>$ maturity stage. The effects of Cd-1 and Cd-3 on Gs were consistent; there was no significant difference between the tillering and booting stages, but their effects were significantly greater than those of the full heading and mature stages. At Cd-2, the Gs value at tillering stage was significantly higher than that at the other growth stages, and there was no significant difference between the booting and full heading stages, but the value was significantly higher than that at maturity stage. For example, Cd-2 and Cd-3 had the same effect on Gs in $\mathrm{XWX}$, and there was no significant difference among the tillering, booting, and full heading stages, but the effect was significantly greater than that at the maturity stage. At Cd-2, the Gs value at the tillering stage was significantly higher than that at the other growth stages, and there was no significant difference between the booting and full heading stages, but it was significantly higher than that at the maturity stage. Ci variation trend: The $\mathrm{Ci}$ value of $\mathrm{Cd}-1$ decreased gradually with the growth period, reaching the lowest value at the full heading stage and then eventually rose again. The $\mathrm{Ci}$ values of $\mathrm{Cd}-2$ and $\mathrm{Cd}-3$ decreased gradually with the extension of the growth period. The change trend of $\operatorname{Tr}$ was as follows: booting stage $>$ full heading stage $>$ tillering stage $>$ maturity stage. The difference between the two varieties was that the lowest value was different; that is, the lowest value of Cd-1 appeared at the full heading stage, while the lowest value of Cd-2 and Cd-3 appeared at the booting stage.

3.3. Cd Uptake Trend of Two Rice Varieties in Cd-Contaminated Fields. Through data processing, it was found that there were significant differences in $\mathrm{Cd}$ content among different Cd concentration pollution treatments, genotypes of rice varieties, and organs (root system, stem sheath, and leaf) at different growth and development stages (Table 4).

3.3.1. Determination of Cd Content in Roots, Stems, Sheaths, and Leaves of Rice. The Cd content in the root system, stem sheath, leaf, and brown rice of YZX was higher than that of XWX (Table 4). The Cd content was significantly affected by different soil concentrations of $\mathrm{Cd}$, and there was an obvious trend in change. The Cd content in the root system, stem sheath, leaf, and brown rice of both YZX and XWX increased with the increase in the $\mathrm{Cd}$ concentration in soil, that is, $\mathrm{Cd}$ $3>$ Cd-2 $>$ Cd-1.

The Cd content in roots, stem sheaths, and leaves was significantly affected by different concentrations of $\mathrm{Cd}$, which increased with the increase in Cd concentration, that is, booting stage $>$ full heading stage $>$ tillering stage$>$ maturity stage.

3.3.2. Determination of Cd Content in Rice Grains. The Cd content in the grains of the two tested varieties increased with the increase in soil Cd concentration (Table 5), that is, 


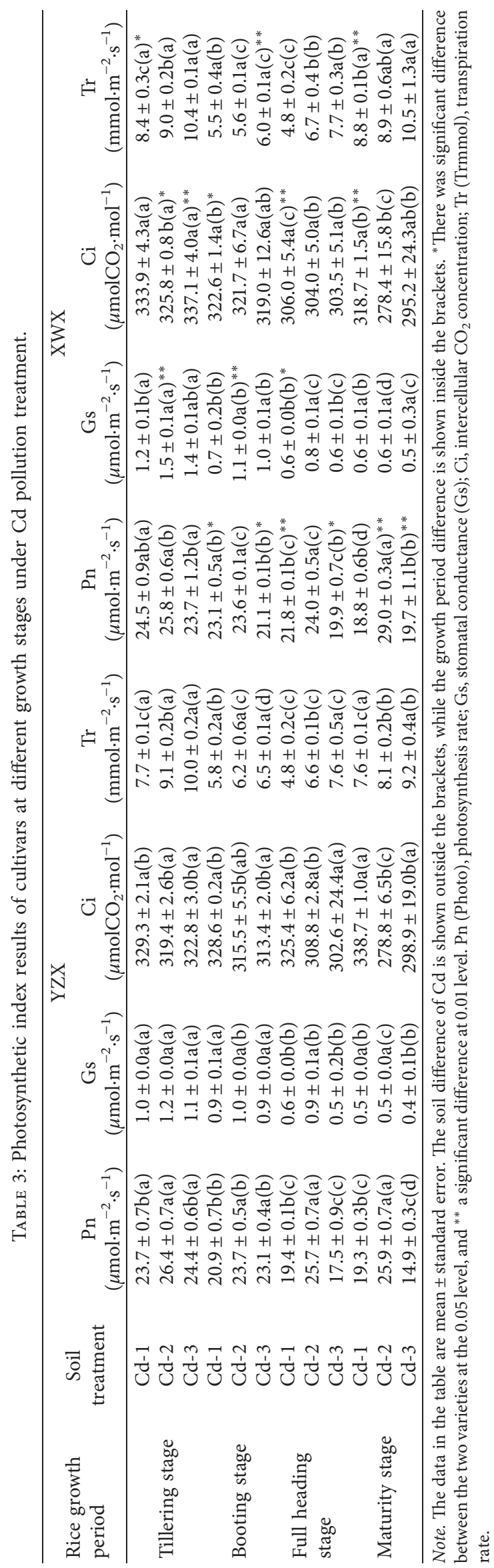




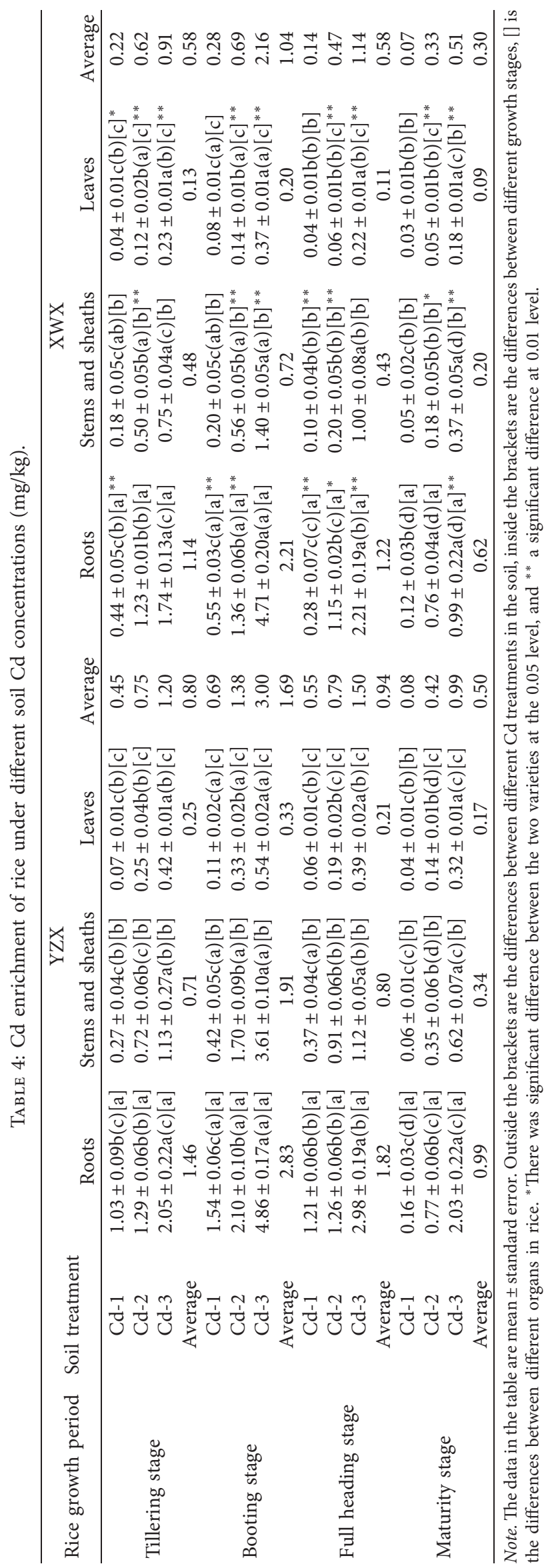


TABLE 5: Cd content in grain under soil treatment with different Cd concentrations.

\begin{tabular}{lccc}
\hline \multirow{2}{*}{ Rice organs } & \multirow{2}{*}{ Soil treatment } & \multicolumn{2}{c}{ Cd content $(\mathrm{mg} / \mathrm{kg})$} \\
& & YZX & XWX \\
\hline \multirow{3}{*}{ Grain } & Cd-1 & $0.02 \pm 0.00 \mathrm{c}$ & $0.01 \pm 0.00 \mathrm{~b}$ \\
& Cd-2 & $0.04 \pm 0.01 \mathrm{~b}$ & $0.02 \pm 0.00 \mathrm{~b}^{* *}$ \\
& Cd-3 & $0.12 \pm 0.00 \mathrm{a}$ & $0.10 \pm 0.01 \mathrm{a}^{*}$ \\
& Average & 0.06 & 0.04
\end{tabular}

Note. Different letters indicated significant differences among soil Cd treatments. ${ }^{*}$ The differences among varieties at the level of 0.05 , and ${ }^{* *}$ a significant difference at 0.01 level.

Cd-1 $<$ Cd-2 $<$ Cd-3 (Figure 1), and there were significant differences between YZX and XWX under three different soil Cd concentrations. Under the $\mathrm{Cd}$ concentration of each soil, the $\mathrm{Cd}$ content in the grains of YZX was higher than that of XWX but was lower than $0.2 \mathrm{mg} / \mathrm{kg}$ in all cases; that is, they did not exceed the threshold value for Cd content in food set by the National Food Safety Standard for Limits of Pollutants in Food [22].

Under the same soil Cd concentration, the Cd content in the grains of YZX was higher than that of XWX, and there was a significant difference. The average values of $\mathrm{Cd}$ in the three soils were 0.06 and $0.04 \mathrm{mg} / \mathrm{kg}$, respectively. Comparatively, the low Cd accumulation in XWX in terms of the $\mathrm{Cd}$ content in rice grains is favorable to that of YZX. Therefore, the higher the initial Cd content in soil, the higher the $\mathrm{Cd}$ content in rice grains.

\section{Discussion}

\subsection{Effects of Cd Pollution on Antioxidant Enzyme Indices of Rice}

4.1.1. SOD Activity. The SOD activities in leaves for YZX and XWX differed according to variety, Cd concentration, and treatment time. The SOD activity of XWX was significantly higher than that of YZX (66.7\%), which indicates that the capacity of XWX to respond to Cd stress is higher than that of YZX. In each growth period, the SOD activity increased with the increase in $\mathrm{Cd}$ concentration, and the differences among different Cd treatments were significant and consistent in trend.

With the increase in the soil Cd concentration, the SOD activity of rice leaves firstly increased and then decreased; that is, the key growth period of rice leaves was the reproductive growth period, and the SOD activity was more sensitive to $\mathrm{Cd}$ at this time. These results indicated that the protective system of antioxidant enzymes was activated when the concentration of $\mathrm{Cd}$ in the environment reached a certain threshold. The change pattern of the enzyme showed an initial increase followed by a decrease, which indicates that the enzyme has a greater potential to allow tolerance of Cd stress, which is consistent with the research results on the entire regeneration forests [23].

4.1.2. POD Activity. POD is an important antioxidant enzyme in plants that can degrade $\mathrm{H}_{2} \mathrm{O}_{2}$ in plants and allow them to avoid damage [24]. In this experiment, with the

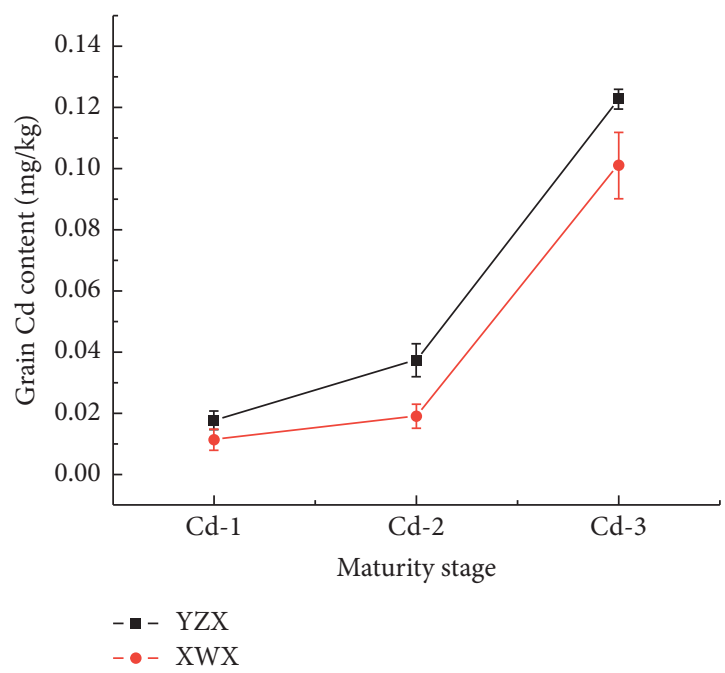

Figure 1: Variation trend of Cd content in seeds at maturity stage.

increase in the Cd pollution concentration, the changes in POD and SOD activities of YZX and XWX were consistent in trend. This is mainly due to the fact that in the life course of rice, the enzymes of the antioxidant system are affected by external factors, such as heavy metal Cd and the internal metabolic process of plant aging [25].

Both varieties tested POD vigor, as the extension of the growth period showed a significantly smaller tendency, namely, the tillering stage $>$ booting stage $>$ full panicle stage of maturity; POD plays a clearly defined free radical role in rice, and the effect of POD activity decreased with the decrease in the mean antioxidant protection ability; this may be due to the level of $\mathrm{Cd}$ stress under the condition of active oxygen free radicals. In other words, the capacity of the enzyme to handle $\mathrm{Cd}$ stress was reached.

4.1.3. CAT Activity. When plants are stressed by heavy metals, CAT activity increases, indicating that CAT can enhance plant resistance [26]. In this experiment, the CAT activity of XWX was higher than that of YZX, and the situation was similar regarding POD activity. With the increase in $\mathrm{Cd}$ pollution concentration, CAT activity increased, which is consistent with previous research results [27].

The CAT activity of YZX and XWX showed a significant difference at different growth stages under the same soil Cd concentration, and the biggest decrease was observed at the full heading stage, indicating that $\mathrm{Cd}$ stress had a great influence on the CAT activity of YZX and XWX under the conditions tested in this experiment. The two varieties showed an increasing trend with the growth period of the two cultivars, and there were significant differences among the growth periods. This indicates that $\mathrm{Cd}$ stress changes greatly as the aging of the plant affects their metabolism. With the extension of the growth period, the adaptability of rice to $\mathrm{Cd}$ is enhanced, the antioxidant protection ability is enhanced, and the difference in CAT activity is gradually reduced. 
4.1.4. MDA Content. MDA can change the fluidity and permeability of the cell membrane, and its content can reflect the degree of damage to the plant membrane system and indicate the ability of the plant to resist stress [28]. In this experiment, the MDA content of YZX and XWX increased with the increase in soil $\mathrm{Cd}$ concentration and the prolongation of treatment time (i.e., growth process). The accumulation of MDA indicated that rice was experiencing stress due to $\mathrm{H}_{2} \mathrm{O}_{2}, \mathrm{O}^{2-}$., $\mathrm{OH}$, and other reactive oxygen radicals, which cause the peroxidation of rice leaf cell membranes [29].

It can be seen from the above results that the growth of rice is affected under soil Cd pollution, and the trend is consistent between the varieties. The MDA content in rice leaves increases significantly, and with the increase in soil Cd concentration, the increase in MDA becomes more obvious [30]. Hence, in response to the increase in soil Cd concentration in this experiment, the activities of SOD, POD, and CAT showed a gradual upward trend, while the MDA concentration showed an opposite or downward trend [31]. There were significant differences in the activities of antioxidant enzymes in different rice varieties under the same and different soil Cd concentrations. It was found that the activities of SOD, POD, and CAT decreased with the increase in $\mathrm{Cd}$ concentration in soil.

\subsection{Effects of Cd Stress on Photosynthetic Parameters of Rice}

4.2.1. Comparison of Photosynthetic Parameters between Varieties. The Pn, Gs, Ci, and Tr of XWX were higher than those of YZX, and the Pn, Gs, and Ci decreased gradually with the prolongation of the growth period; only $\mathrm{Tr}$ was the lowest at the full heading stage and then eventually rose again. The results of this experiment showed that between the two rice varieties with different Cd tolerance, XWX had a lower variation range of photosynthetic parameters than YZX. Comparatively, XWX had a stronger tolerance to Cd in the soil than YZX [32], which could protect itself from environmental damage.

4.2.2. Comparison of Photosynthetic Parameters with Different $\mathrm{Cd}$ Concentrations. The Pn, Gs, $\mathrm{Ci}$, and $\mathrm{Tr}$ of different varieties were highest in $\mathrm{Cd}-2$, followed by $\mathrm{Cd}-3$, and the lowest in Cd-1, that is, Cd-2 > Cd-3 > Cd-1. In addition, Pn, $\mathrm{Gs}$, and $\mathrm{Ci}$ decreased gradually with the prolongation of the growth period, and $\operatorname{Tr}$ was the lowest at the full heading stage and then eventually rose again.

Previous studies have shown that $\mathrm{Cd}$ stress in rice seedlings leads to decreased photosynthetic parameters (such as photosynthetic rate, transpiration rate, and stomatal conductance) in leaves. The $\mathrm{Tr}$ of rice photosynthesis is negatively correlated to $\mathrm{Cd}$ concentration, i.e., the higher the $\mathrm{Cd}$ concentration, the lower the $\operatorname{Tr}$ [33]. In this experiment, the Pn and Gs of YZX and XWX had a promoting effect on the photosynthesis of rice plants under the low-concentration treatment. When the $\mathrm{Cd}$ concentration increases to a certain threshold, the photosynthetic rate peaks and then gradually declines [34].
The change trends were the same for both varieties. The $\operatorname{Tr}$ value of XWX was higher than that of YZX, but the difference was not significant, indicating that for XWX in a certain period, the transpiration of water per unit leaf area was slightly higher than that of YZX, so as to cope with the damage caused by $\mathrm{Cd}$ pollution to the plants. Throughout the entire rice growth period, Pn and Gs present a decreasing trend with increases in the soil $\mathrm{Cd}$ concentration, and the research results of Chen [35] and also of Xiao [36], which show that stomatal openness affects the efficiency of gas exchange, support our results in the rice heading stage. In contrast to Pn and Gs, Ci first decreased and then increased, which was different from the results of Wang et al. [37] and James [38] that indicated the rise and fall of Pn were caused by nonstomatal restriction. This may be due to the restriction of RuBP carboxylation, photosynthetic activity, and inorganic phosphorus, which hinders $\mathrm{CO}_{2}$ utilization [39]; this is consistent with the research results of Zhang et al. [40]. In general, there was a positive correlation among Pn, Gs, and $\mathrm{Tr}$ and a negative correlation with $\mathrm{Ci}$. At the same time, the high concentration of $\mathrm{Cd}$ inhibited Pn and Gs, both of which decreased simultaneously, while $\mathrm{Ci}$ and $\mathrm{Tr}$ increased, indicating that nonstomatal limiting factors led to a decrease in $\mathrm{Tr}$.

4.2.3. Trend in the Variation of Photosynthetic Parameters among Different Growth Stages. The four indexes of Pn, Gs, $\mathrm{Ci}$, and $\mathrm{Tr}$ of both varieties showed the following values in four growth stages: tillering stage $>$ booting stage $>$ full heading stage $>$ maturity stage. Both Pn and Gs showed that Cd-2 was higher than Cd-1 and Cd-3, presenting a "pyramid" trend. Ci decreased with the increase in soil $\mathrm{Cd}$ concentration, while $\mathrm{Tr}$ and $\mathrm{Ci}$ showed the opposite trend; that is, they increased with the increase in soil $\mathrm{Cd}$ concentration.

\subsection{Cd Uptake by Two Rice Varieties in Cd-Contaminated Rice Fields}

4.3.1. Comparison of Cd Accumulation between Two Rice Varieties. Studies [41] have shown that, under the same Cd stress, different rice varieties have different performances in $\mathrm{Cd}$ absorption, accumulation, and distribution in paddy soil due to interspecific (different species and genera) and intraspecific (different varieties or varieties) differences. For the same growth period of the same rice organs under the same $\mathrm{Cd}$ soil concentration, most of the experimental treatments showed that the Cd content of YZX was significantly higher than that of XWX; only a small number of experimental treatments showed no significant difference between the two varieties, namely, only the organs (root, stem sheath, and leaf) of Cd-1 at the maturity stage. There was no significant difference in the $\mathrm{Cd}$ content in the roots of rice varieties at the $\mathrm{Cd}-2$ tillering and $\mathrm{Cd}-3$ booting stages (a total of five treatments, accounting for $13.89 \%$ of the total treatments), but the Cd content in YZX was significantly higher than that in XWX. Relatively, YZX absorbs Cd more easily than XWX. 
4.3.2. Comparison of $C d$ Accumulation under Three Cd Concentration Gradients. The Cd content of rice increased significantly with the increase in the soil Cd concentration for the same growth period and the same rice variety in the same rice organ. Taking the tillering stage as an example, the root Cd content of Cd-3 was $(2.05 \mathrm{mg} / \mathrm{kg})>\mathrm{Cd}-2(1.29 \mathrm{mg} /$ $\mathrm{kg})>\mathrm{Cd}-1(1.03 \mathrm{mg} / \mathrm{kg})$, and the $\mathrm{Cd}$ content of Cd-3 was significantly higher than that of $\mathrm{Cd}-1$ and $\mathrm{Cd}-2$, but there was no significant difference between $\mathrm{Cd}-1$ and $\mathrm{Cd}-2$. When reaching the booting stage, the root $\mathrm{Cd}$ content of $\mathrm{Cd}-3$ was $(4.86 \mathrm{mg} / \mathrm{kg})>\mathrm{Cd}-2(2.10 \mathrm{mg} / \mathrm{kg})>\mathrm{Cd}-1(1.54 \mathrm{mg} / \mathrm{kg})$, and there were significant differences among different treatments. Therefore, the higher the original Cd content in the soil, the more the $\mathrm{Cd}$ absorbed by rice.

4.3.3. Change Trend in Cd Accumulation among Different Growth Periods. The accumulation of Cd differs greatly depending on the growth stages of rice. Zhao et al. [42] examined the whole growth period and found that the $\mathrm{Cd}$ uptake trend of different organs of different varieties was inconsistent at each growth period. The Cd content in the roots, stems, and leaves of rice at the booting stage was significantly higher than that at the other growth stages, while the $\mathrm{Cd}$ content in various organs of rice at other growth stages fluctuated. The average Cd content of three kinds of soil at different growth stages was as follows: booting stage $(1.69 \mathrm{mg} / \mathrm{kg})>$ full heading stage $(0.94 \mathrm{mg} /$ $\mathrm{kg})>$ tillering stage $(0.80 \mathrm{mg} / \mathrm{kg})>$ maturity stage $(0.50 \mathrm{mg} /$ $\mathrm{kg})$; in XWX, booting stage $(1.04 \mathrm{mg} / \mathrm{kg})>$ full heading stage $(0.58 \mathrm{mg} / \mathrm{kg})=$ tillering stage $(0.58 \mathrm{mg} / \mathrm{kg})>$ maturity stage $(0.30 \mathrm{mg} / \mathrm{kg})$. Therefore, the booting stage is the key stage in rice, where $\mathrm{Cd}$ absorption is highest. However, fluctuation was observed in both the root and leaf, and no obvious trend was found. In XWX, there was no correlation with the growth stage, but the highest $\mathrm{Cd}$ content was found in all organs at the booting stage (average value was $1.05 \mathrm{mg} / \mathrm{kg}$ ). Peng et al. [43] used hydroponic experiments to add exogenous $\mathrm{Cd}$ at different growth stages of rice, and the results showed that $\mathrm{Cd}$ exposure at the booting and heading stages contributed significantly to $\mathrm{Cd}$ accumulation in rice. Under the condition of high Cd, Tang et al. [44] found that the biomass of rice with high $\mathrm{Cd}$ accumulation increased gradually with the extension of the growth period, and there was a positive correlation between $\mathrm{Cd}$ accumulation in shoots of rice with high $\mathrm{Cd}$ accumulation and the whole plant, and the Cd accumulation rate in the shoots and the whole plant reached the maximum at the filling stage.

\subsubsection{Analysis of Cd Accumulation in Different Rice Organs.} As the most important nutrient-acquiring organ, the rice root absorbs and accumulates minerals and other nutrient elements while introducing $\mathrm{Cd}$ into the system. Its ability to introduce $\mathrm{Cd}$ into the system depends on the $\mathrm{Cd}$ content in the environment and the transport efficiency of metal ion channels in the root system [45-48]. Ju et al. [49] found that nutrient elements in roots, stems, and leaves enter grains via the cob, and the final Cd content in grains is determined by the Cd concentration in the cob, which is highly positively correlated [50]. In this experiment, the Cd content in the roots of rice was significantly higher than that in stems, sheaths, and leaves under the same soil Cd concentration for the same variety and growth period. The Cd content of the stem sheath was significantly higher than that of the leaf in most experimental treatments. Taking the tillering stage as an example, the average $\mathrm{Cd}$ contents in different organs of three soils under the Cd concentration were as follows: root $(1.46 \mathrm{mg} / \mathrm{kg})$, stem sheath $(0.71 \mathrm{mg} / \mathrm{kg})$, and leaf $(0.25 \mathrm{mg} /$ $\mathrm{kg}$ ). Therefore, the root system of rice is the most important organ to absorb $\mathrm{Cd}$. The $\mathrm{Cd}$ content in all organs of the rice plant is highest in the root system, followed by the stem and sheath leaves, and the least in the grain, that is, root $>$ stem and sheath $>$ leaf $>$ grain, which is consistent with the previous research results of screening varieties or breeding intermediate materials with low Cd absorption or low accumulation in the grain by artificially adding Cd [51-54]. The Cd content of YZX was higher than that of XWX but was lower than $0.2 \mathrm{mg} / \mathrm{kg}$ in all cases and does not exceed the levels specified in the safety standard for Cd intake in food.

\section{Conclusions}

The activity of SOD, POD, and CAT of XWX was higher than that of YZX, but the content of MDA was the opposite. SOD, POD, and CAT all increased with the increase in Cd concentration, while the MDA content decreased in the three contaminated soils with different $\mathrm{Cd}$ concentrations. Through the comparative analysis of photosynthetic physiology, it was found that the low-Cd-accumulating rice, XWX, was more tolerant to Cd in the Cd-polluted soil, while the high-Cd-accumulating rice, YZX, was more sensitive. The Cd absorption trend of the two tested varieties was consistent: the booting stage is the key stage of $\mathrm{Cd}$ absorption of all four growth stages, in which Cd levels peak. Under different soil Cd concentrations, the Cd content in all organs of rice plants increased with the increase in soil $\mathrm{Cd}$ concentrations. The trend in Cd content for all organs is that the farther away they are from the root, the lower the Cd content.

\section{Data Availability}

The data supporting these results are available from the corresponding author upon request.

\section{Conflicts of Interest}

The authors declare that they have no conflicts of interest.

\section{Acknowledgments}

This research was financially supported by the National Natural Science Foundation of China (No. 41907032), the Science and Technology Support Project of Guizhou Province (Nos. 2018.2295 and 2019.2305), and the Key Scientific and Technological Special Project of Changsha City in China (No. kq200602019.230526). 


\section{References}

[1] W. X. Chen, Q. Li, Z. Wang, and Z. J. Sun, "Spatial distribution characteristics and pollution evaluation of heavy metals in arable Land soil of China," Environmental Sciences, vol. 41, no. 6, pp. 2822-2833, 2020.

[2] Ministry of Environmental Protection and Ministry of Land and Resources, "National soil pollution survey bulletin," 2014, http://www.gov.cn/foot/site1/20140417/ 782bcb88840814ba158d01.pdf.

[3] D.-F. Huang, L. L. Xi, L. N. Yang, Z. Q. Wang, and J. C. Yang, "Comparisons in agronomic and physiological traits of rice genotypes differing in cadmium-tolerance," Acta Agronomica Sinica, vol. 34, no. 5, pp. 809-817, 2008.

[4] J. Guo, Y. Yao, X. X. Zhao, J. P. Liu, and T. Wang, "Pollution status of lead and cadmium ions in grain and its harm to human," Grain science and technology and economy, vol. 43, no. 3, pp. 33-35, 2018.

[5] G. Arindam, C. Palak, and W. Wolfram, "Metabolomics in plant stress physiology," Plant Genetics and Molecular Biology, vol. 164, pp. 187-236, 2018.

[6] X. R. Shen, M. Y. Dong, C. Y. Wang, J. Wang, and Q. Zhou, "Effects of high manganese stress on the mineral element absorption and photosynthetic system of vetiver grass," Journal of Agro-Environment Science, vol. 38, no. 10, pp. 2297-2305, 2019.

[7] S. Y. Yang, X. Y. Chen, W. K. Hui, Y. Ren, and L. Ma, "Progress in responses of antioxidant enzyme systems in plant to environmental stresses," Journal of Fujian Agriculture and Forestry University (Natural Science Edition), vol. 45, no. 5, pp. 481-489, 2016.

[8] S. Chen, Q. Wang, H. Lu et al., "Phenolic metabolism and related heavy metal tolerance mechanism in Kandelia Obovata under Cd and Zn stress," Ecotoxicology and Environmental Safety, vol. 169, pp. 134-143, 2019.

[9] C. G. Sanbon, L. Yaniv, and M. Menachem, "Quantitative and comparative analysis of whole-plant performance for functional physiological traits phenotyping: new tools to support pre-breeding and plant stress physiology studies," Plant Science, vol. 282, pp. 49-59, 2019.

[10] Y. Z. Zhang, B. H. Fang, Z. N. Teng, G. H. Chen, and Y. Liu, "Screening and verification of rice varieties with low cadmium accumulation," Agricultural Science and Technology, vol. 20, no. 3, pp. 1-10, 2019.

[11] Ministry of Environmental Protection of the People's Republic of China, Soil Quality-Determination of Lead, Cadmium-Graphite Atomic Absorption Spectrophotometry, China Standards Press, Beijing, China, 1997.

[12] General Administration of Quality Supervision, Inspection and Quarantine of the People's Republic of China, Soil Quality-Analysis of Available Lead and Cadmium Contents in Soils-Atmic Absorption spectrometry, China Standards Press, Beijing, China, 2009.

[13] Ministry of Environmental Protection of the People's Republic of China, Soil Quality-Determination of Total NitrogenModified Kjeldahl method, China Standards Press, Beijing, China, 2015.

[14] Sichuan Provincial Bureau of Quality and Technical Supervision, Soil-Determination of Alkali-Hydrolyzable nitrogen, Sichuan Standards Press, Chengdu, China, 2015.

[15] The Ministry of Agriculture of the People's Republic of China, Method for Determination of Soil Total phosphorus, China Standards Press, Beijing, China, 1988.
[16] The Ministry of Agriculture of the People's Republic of China, Soil Testing-Part 7: Method for Determination of Available Phosphorus in Soil, China Standards Press, Beijing, China, 2014.

[17] The Ministry of Agriculture of the People's Republic of China, Method for Determination of Total Potassium in soils, China Standards Press, Beijing, China, 1988.

[18] The Ministry of Agriculture of the People's Republic of China, Determination of Exchangeable Potassium and Non-exchangeable Potassium Content in soil, China Standards Press, Beijing, China, 2004.

[19] The Ministry of Agriculture of the People's Republic of China, Soil Testing Part 2: Method for Determination of Soil pH, China Standards Press, Beijing, China, 2006.

[20] The Ministry of Agriculture of the People's Republic of China, Soil Testing Part 6: Method for Determination of Soil Organic matter, China Standards Press, Beijing, China, 2006.

[21] L. Sun, X. Xu, Y. Jiang et al., "Genetic diversity, rather than cultivar type, determines relative grain Cd accumulation in hybrid rice," Frontiers of Plant Science, vol. 7, p. 1407, 2016.

[22] National Health and Family Planning Commission of the People's Republic of China and National Food and Drug Administration of the People's Republic of China, Food Safety National Standard Limits of Contaminants in food, China Standards Press, Beijing, China, 2017.

[23] Q. L. Dai, Ariety differences of Zea mays in response to cadmium $(\mathrm{Cd})$ or lead $(\mathrm{Pb})$ stress and mechanisms, Ph.D. thesis, Sun Yat-sen University, Guangzhou, China, 2005.

[24] X. L. Jiang, Z. X. Li, and Z. S. Kang, “The recent progress of research on peroxidase in plant disease resistance," Journal of Northwest Forestry University, vol. 6, pp. 124-129, 2001.

[25] F. M. Yu, K. H. Liu, H. Liu, H. Deng, and Z. M. Zhou, "Antioxidative responses to cadmium stress in the leaves of Oryza saliva L. in different growth period," Ecology and Environmental Sciences, vol. 21, no. 1, pp. 88-93, 2012.

[26] Z. Y. Chen, X. Y. Fei, F. Sun, and X. Y. Cui, "Effects of salinealkali stress on activities and gene expression of antioxidant enzymes of transgenic $L c$-CDPK rice," Journal of Northwest Forestry University, vol. 47, no. 5, pp. 15-22, 2019.

[27] A. Z. Yang, S. M. Duan, W. G. Wu, and G. Chen, "Effects of drought stress at booting stage on physiological index and yield of super rice," Molecular Plant Breeding, vol. 15, no. 2, pp. 685-691, 2017.

[28] X. H. Song, "The effect of $\mathrm{Cd}$ sang $\mathrm{Cd}+$ high temperature stress to the growth and the antioxidant system of the double antioxidase transgenic rice," Master's thesis, Shandong Normal University, Jinan, China, 2008.

[29] F. Liu, C. Qu, Y. Wang, and G. H. Chen, "Effects of drought rewatering at heading stage on antioxidant enzyme activity and root activity of machine-transplanted rice," Journal of Southern Agriculture, vol. 51, no. 1, pp. 65-71, 2020.

[30] J. D. Chen, Research on difference and mechanism of rice response under cadmium stress and regulation, Ph.D. thesis, Yangzhou Nuiversity, Yangzhou, China, 2013.

[31] T. Z. Li, A. T. Chen, C. Li, D. Yang, and N. He, "Effects of silicon on growth and physiological responses of rice seedlings under cadmium stress," Journal of Agro-Environment Science, vol. 37, no. 6, pp. 1072-1078, 2018.

[32] Z. N. Teng, B. H. Fang, Y. Liu, Y. He, and J. Yang, "Effects of $\mathrm{Cd}$ on photosynthesis of different rice varieties," Chinese Journal of Agrometeorology, vol. 37, pp. 538-544, 2016.

[33] F. Gao, Y.-J. Lin, J.-L. Zhang et al., "Effects of cadmium stresses on physiological characteristics, pod yield, and seed 
quality of peanut," Acta Agronomica Sinica, vol. 37, no. 12, pp. 2269-2276, 2012.

[34] Y. L. Sun, H. M. Liu, and Q. G. Xu, "Effect of cadmium stress on photosynthetic characteristics and physiological and biochemical traits during seedling stage of different rice cultivars," Acte Agriculturae Boreali-Simica, vol. 32, pp. 176-181, 2017.

[35] Y. W. Chen, "The study of the infect of photosynthetic characteristics and the absorption of related nutritents of rice materials and hybrids under cadumium stress," Master's thesis, Agricultural University of Sichuan, Chengdu, China, 2011.

[36] Q. T. Xiao, "Physiogical response in rice (Oryza sative L.) under cadmium stress conditions," Master's thesis, Fujian Agriculture and Forestry University, Fuzhou, China, 2011.

[37] H. Wang, S. Yan, H. Xin et al., "A subsidiary cell-localized glucose transporter promotes stomatal conductance and photosynthesis," The Plant Cell, vol. 31, no. 6, pp. 1328-1343, 2019.

[38] A. B. James, "Effects of pulses of elevated carbon dioxide concentration on stomatal conductance and photosynthesis in wheat and rice," Physiologia Plantarum, vol. 149, no. 2, pp. 214-221, 2013.

[39] C. Z. Li, Y. L. Sun, H. M. Liu, and Q. G. Xu, "The difference of seedling growth and photosynthetic performance of different rice varieties under cadmium stress," Journal of Hunan Agricultural University, vol. 47, no. 2, pp. 147-152, 2021.

[40] X. Y. Zhang, Y. Cao, J. Meng, G. C. Zhou, and H. N. Zhang, "Effects of biochar on growth and photosynthetic yield of rice under cadmium environment," Jiangsu Agricultural Sciences, vol. 44, no. 5, pp. 97-101, 2016.

[41] C. G. Yang, X. Y. Liao, X. F. Zhang, Z. W. Zhu, and M. X. Chen, "Genotypic difference in cadmium accumulation in Brown rice," Chinese Journal of Rice Science, vol. 20, pp. 660-662, 2006.

[42] J. L. Zhao, S. H. Zhang, T. F. Yang, J. F. Dong, and Q. Liu, "Phenotype evaluation of $\mathrm{Cd}$ accumulation of 181 diverse indica germplasm at seedling and mature stages," Molecular Plant Breeding, vol. 16, no. 18, pp. 6080-6087, 2018.

[43] O. Peng, B. Q. Tie, C. C. Ye, M. Zhang, and X. L. Liu, "The key period of cadmium accumulation in rice," Journal of Agricultural and Resource Economics, vol. 34, no. 3, pp. 272-279, 2017.

[44] H. Tang, T. X. Li, X. Z. Zhang, H. Y. Yu, and G. D. Chen, "Cadmium accumulation in high cadmium-accumulating rice cultivars at different growth stages," Journal of Agriculture and Environment Science, vol. 34, no. 3, pp. 471-477, 2015.

[45] F. F. Nocito, C. Lancilli, B. Dendena, G. Lucchini, and G. A. Sacchi, "Cadmium retention in rice roots is influenced by cadmium availability, chelation and translocation," Plant, Cell and Environment, vol. 34, no. 6, pp. 994-1008, 2011.

[46] S. Akimasa, N. Yamaji, K. Yokosho, and J. F. Ma, "Nramp5 is a major transporter responsible for manganese and cadmium uptake in rice," The Plant Cell Online, vol. 24, no. 5, pp. 2155-2167, 2012.

[47] Z. W. Zhu, C. X. Chen, R. X. Mou, Z. Y. Cao, and W. X. Zhang, "Advances in research of cadmium metabolism and control in rice plants," Scientia Agricultura Sinica, vol. 47, no. 18, pp. 3633-3640, 2014.

[48] G. Deng, G. Wang, M. F. Sun, and J. W. Peng, "Accumulation and distribution of Cadmium in different rice varieties under cadmium stress," Journal of Zhejiang Agricultural Sciences, vol. 57, no. 4, pp. 468-471, 2016.
[49] X. H. Ju, C. B. Zhang, Z. G. Song, L. N. Han, and Z. Y. Lu, "Changes in cadmium accumulation in rice organs during grain development and their relationship with genotype and cadmium levels in soil," Plant Physiology Journal, vol. 50, no. 5, pp. 634-640, 2014.

[50] Q. L. Cai, D. S. Lin, G. Wang, and D. Wang, "Differences in cadmium accumulation and transfer capacity among different types of rice cultivars," Journal of Agriculture and Environment Science, vol. 35, no. 6, pp. 1028-1033, 2016.

[51] Y. H. Chen, J. G. Li, T. Yang, J. Xie, and L. G. Wei, "Research on accumulation characteristic and correlation of cadmium in various rice varieties," Acta Agriculturae Jiangxi, vol. 29, no. 9, pp. 10-14, 2017.

[52] X. L. Long, X. C. Xiang, Y. F. Xu, W. L. Su, and C. F. Liao, "Absorption, transfer and distribution of $\mathrm{Cd}$ in indica and japonica rice under Cd stres," Chinese Journal of Rice Science, vol. 28, no. 2, pp. 177-184, 2014.

[53] J. Liu, M. Qian, G. Cai, J. Yang, and Q. Zhu, "Uptake and translocation of $\mathrm{Cd}$ in different rice cultivars and the relation with Cd accumulation in rice grain," Journal of Hazardous Materials, vol. 143, no. 1-2, pp. 443-447, 2007.

[54] X. D. Hu, "Effects of soil cadmium pollution and $\mathrm{p} \mathrm{H}$ on cadmium accumulation in different rice varieties," Master's thesis, Agricultural University of Hunan, Changsha, China, 2018. 